\title{
Avaliação da atividade antimicrobiana de extratos de Dioclea grandiflora Mart. ex. Benth., Fabaceae
}

\author{
Luiz Lúcio Soares da Silva, ${ }^{* 1}$ Edeltrudes de Oliveira Lima, ${ }^{1}$ Silene Carneiro do Nascimento, ${ }^{2}$ \\ Diógenes Luiz da Mota, ${ }^{3}$ Nicassio Henrique da Silva, ${ }^{4}$ Edvaldo Rodrigues de Almeida, ${ }^{2}$ \\ Marta Gerusa Soares da Silva ${ }^{5}$
}

\author{
${ }^{1}$ Laboratório de Tecnologia Farmacêutica "Prof. Delby Medeiros", Universidade Federal da Paraíba, \\ 58051-970 João Pessoa-PB, Brasil \\ ${ }^{2}$ Departamento de Antibióticos, Universidade Federal de Pernambuco, Avenida Prof. Moraes Rego s/n, \\ 50670420 Recife-PE, Brasil
}

${ }^{3}$ Departamento de Histologia e Embriologia, Universidade Federal de Pernambuco, Avenida Prof. Moraes Rego s/n, 50670420 Recife-PE, Brasil

${ }^{4}$ Departamento de Bioquímica, Laboratório de Produtos Naturais, Universidade Federal de Pernambuco, Avenida Prof. Moraes Rego s/n, 50670420 Recife-PE, Brasil

${ }^{5}$ Departamento de Zootecnia, Universidade Federal Rural de Pernambuco, Dois Irmãos, 50.000 Recife-PE, Brasil.

\begin{abstract}
RESUMO: A espécie Dioclea grandiflora Mart. ex. Benth., Fabaceae é uma planta que pertence à família Fabaceae, popularmente conhecida como mucunã-de-caroço e olho-de-boi, e, encontra-se distribuída nas regiões da caatinga e serrado do Brasil. Os extratos aquoso, etanólico e hidroalcoólico da casca do caule, da casca da raiz e da folha de D. grandiflora, nas concentrações de $313 \mu \mathrm{g} /$ $\mathrm{mL}$ a $10.000 \mu \mathrm{g} / \mathrm{mL}$, foram analisados por meio de técnica de difusão em ágar, frente a vinte microrganismos representantes de bactérias Gram positivas, Gram negativas, fungos filamentosos e leveduras. $\mathrm{O}$ extrato aquoso da casca do caule, na concentração de $10.000 \mu \mathrm{g} / \mathrm{mL}$, inibiu o crescimento de Staphylococcus aureus com halo de $20 \mathrm{~mm}$. Já o extrato hidroalcoólico da casca do caule inibiu apenas $S$. aureus com halo de $18 \mathrm{~mm}$, enquanto o extrato da folha inibiu o crescimento de dois dermatófitos, Trichophyton mentagrophytes e Microsporum canis. Por outro lado, o extrato hidroalcoólico da casca da raiz inibiu apenas $M$. canis com halo de $15 \mathrm{~mm}$ de diâmetro. Das frações do extrato aquoso da folha, apenas acetato de etila inibiu o crescimento de Streptococcus epidermides, Candida albicans, T. metagrophytes e M. canis. Para o extrato etanólico do caule, a fração aquosa inibiu $S$. epidermides e $S$. aureus.
\end{abstract}

Unitermos: Dioclea grandiflora, Fabaceae, atividade antimicrobiana, produtos naturais.

\begin{abstract}
Evaluation of antibacterial activity of Dioclea grandiflora Mart. ex. Benth., Fabaceae extracts". The species Dioclea grandiflora Mart. ex. Benth., Fabaceae is a plant that belongs to the Fabaceae family, popularly known as "mucunã-de-caroço" and "olho-de-boi". It can be found distributed in mountainous regions and in the scrub savanna of Brazil. The aqueous, ethanol and hydroalcoholic extracts of stem bark, root bark and leaves of D. grandiflora on concentration from $313 \mu \mathrm{g} / \mathrm{mL}$ to $10.000 \mu \mathrm{g} / \mathrm{mL}$, were analyzed by the agar diffusion technique, front to twenty microorganisms, representatives of Gram-positive and Gram-negative bacteria, filamentous fungi and yeasts. The aqueous extract of stem bark, on concentration of $10.000 \mu \mathrm{g} /$ $\mathrm{mL}$, inhibited the growth of Staphylococcus aureus with a $20 \mathrm{~mm}$ halo. Hydroalcoholic extract of stem bark only inhibited $S$. aureus with a halo of $18 \mathrm{~mm}$, while leaves extract inhibited the growth of two dermatophytes, Trichophyton mentagrophytes and Microsporum canis. On the other hand, hydroalcoholic extract of root bark only inhibited $M$. canis with a halo of $15 \mathrm{~mm}$ diameter. From the fractions of aqueous extract of leaves, only ethyl acetate inhibited the growth of Streptococcus epidermides, Candida albicans, T. mentagrophytes e M. canis. For the ethanol extract of stem bark, the aqueous fraction inhibited $S$. epidermides and $S$. aureus.
\end{abstract}

Keywords: Dioclea grandiflora, Fabaceae, antimicrobial activity, natural products. 


\section{INTRODUÇÃO}

A utilização das plantas com atividades terapêuticas é uma das práticas mais antigas empregadas, pelo homem, para cura das suas enfermidades. Grande parte das informações advém do conhecimento popular, quanto ao uso das plantas e seus possíveis efeitos curativos. (Funke \& Melzing, 2006; Biavatti et al., 2007; Oliveira et al., 2007 ; Agra et al., 2007). A Organização Mundial de Saúde (OMS) estima que $80 \%$ da população do mundo utilizam plantas medicinais como principal recurso no atendimento básico de saúde, e vem incentivando tal prática (Elizabetsky, 1993; WHO, 2002).

A planta Dioclea grandiflora Mart. ex. Benth é uma planta pertencente à família Fabaceae. É conhecida popularmente como mucunã, mucunã-de-caroço e olho-deboi, e encontra-se distribuída nas regiões de Caatinga e do cerrado do nordeste brasileiro. Suas sementes e raízes são também utilizadas pela população em formas de infusos nos distúrbios renais e prostáticos (Agra,1996 ). Desta planta foi isolado e identificado diocleína, que induziu um efeito analgésico em roedores (Batista, 1993). Mattei e colaboradores (1995) examinaram a ação farmacológica central das sementes da Dioclea grandiflora e detectaram uma possível atividade ansiolítica. Posteriormente, Bhattacharyya e colaboradores (1997) isolaram e identificaram o dioclenol da casca da raiz dessa planta. Jenkins e colaboradores (1999) isolaram e identificaram o agradol, paraibanol e o diosalol, também da casca da raiz de Dioclea grandiflora. Ainda foi detectado um potencial vaso relaxante no endotélio da aorta de ratos, a partir da diocleína (Lemos et al, 1999). A atividade farmacológica do dioclenol e da dioflorina foi demonstrada por Almeida e colaboradores (2000) em modelos experimentais de analgesia. Almeida e colaboradores (2003) demonstraram o efeito antinoceptivo central do extrato hidroalcoólico das sementes de Dioclea grandiflora sobre roedores. O presente trabalho tem como objetivo analisar a atividade antimicrobiana dos extratos e frações obtidas da casca do caule de Dioclea grandiflora frente a microorganismos patogênicos (fungos e bactérias).

\section{MATERIAL E MÉTODOS}

\section{Material vegetal}

Folha, casca do caule e da raiz de Dioclea grandiflora Mart. ex. Benth., Fabaceae, foram coletadas no município de Santa Rita no Estado da Paraíba, no mês de junho de 2001. O material botânico foi identificado pela Professora $\mathrm{Dr}^{\mathrm{a}}$. Maria de Fátima Agra, do Laboratório de Tecnologia Farmacêutica do Centro de Ciências da Saúde da Universidade Federal da Paraíba e sua exsicata encontra-se depositada no Herbário Lauro Pires Xavier (PPB), sob o código 444-JPB, MO.

\section{Preparação de extratos para o ensaio microbiológico}

Para extração aquosa da casca do caule, da casca da raiz e da folha, foram utilizados $100 \mathrm{~g}$ de cada material, previamente seco e pulverizado, individualizado, adicionado água destilada e submetido à agitação mecânica por $1 \mathrm{~h} \mathrm{e}$, em seguida, deixado em repouso por $24 \mathrm{~h}$. Após o período da extração, cada extrato foi filtrado, submetido à liofilização e acondicionado no freezer, até o momento dos testes de atividade antimicrobiana. $\mathrm{Na}$ obtenção dos extratos hidroalcoólicos, $100 \mathrm{~g}$ do material seco e pulverizado foi colocado em Becker, separadamente, adicionado uma mistura hidroalcoólica $(1: 1)$ e colocado em banho-maria durante $1 \mathrm{~h} \mathrm{a} 80{ }^{\circ} \mathrm{C}$ sob agitação. Em seguida, os extratos foram concentrados sob pressão reduzida, em evaporador rotatório $\left(40^{\circ} \mathrm{C}\right)$, e posteriormente submetido à liofilização.Os extratos brutos alcoólicos da folha, casca do caule e casca da raiz foram obtidos, a partir de $100 \mathrm{~g}$ de cada material seco e pulverizado. Cada material foi colocado em extrator Soxhlet e extraído com etanol $95 \%$, por esgotamento, em uma temperatura de 81 ${ }^{\circ} \mathrm{C}$, por um período de $72 \mathrm{~h}$. Após esta etapa, os extratos foram concentrados sob pressão reduzida em evaporador rotatório $\left(40^{\circ} \mathrm{C}\right)$.

\section{Cromatografia em coluna}

Cerca de $3 \mathrm{~g}$ do extrato etanólico da casca do caule e cerca de $3 \mathrm{~g}$ do extrato aquoso da folha foram submetidos a cromatografia de coluna de sílica gel 70-230 mesh $250 \mathrm{~g}(6 \times 45 \mathrm{~cm})$. Após sedimentação da sílica, $3 \mathrm{~g}$ do extrato etanólico da casca do caule, dissolvido na mistura de acetato de etila e metanol $(1: 1 \mathrm{v} / \mathrm{v})$, foi colocado no topo da coluna, seguindo-se a uma eluição utilizando-se um gradiente crescente de polaridade: acetato de etila, acetato de etila e metanol $(1: 1 \mathrm{v} / \mathrm{v})$, metanol e água. Da mesma forma, realizaram-se os mesmos procedimentos para o extrato aquoso da folha. As frações de cada eluição foram submetidas a testes de atividade antimicrobiana.

\section{Microrganismos e meios}

Os microrganismos selecionados para o estudo foram representantes dos grupos de bactérias Gram-positivas (Staphylococcus aureus ATCC-6538; Streptococcus epidermidis ATCC-12228), Gram-negativas (Escherichia coli LM-209; Psudomonas aeruginosa LM-36), fungos filamentosos (Trichophyton rubrum LM-05; Trichophyton rubrum LM-09; Trichophyton mentagrophytes LM-06; Microsporum canis LM-819; Aspergillus flavus LM-27; Aspergillus parasiticus LM130; Penicillum sp. LM-131; Fusarium sp. LM-135; Geotrichum candidum LM-23) e leveduriformes (Candida albicans ATCC-76615; Candida albicans LM-17; Candida tropicales LM-25; Candida guilliermondii LM16; Candida krusei LM-07 Cryptococcus neoformans LM- 
214; Trchosporon inkin LM-267). Esses microorganismos foram oriundos de coleção de material clinico e de meio ambiente, e se encontram catalogados no Laboratório de Micologia do Departamento de Ciências Farmacêuticas da Universidade Federal da Paraíba. Para realização dos ensaios microbiológicos in vitro pelo método de difusão em meio sólido, foram usados Agar Muller-Hinton (Merck) e Agar Sabouraud dextrose a 2\%-ASD, respectivamente, para bactérias e fungos.

\section{Ensaios de atividade antimicrobiana}

\section{Preparação do inoculo}

O inóculo foi preparado, partindo-se de culturas recentes das cepas bacterianas e fúngicas, mantidas, respectivamente, em agar Muller-Hinton e agar Sabouraud dextrose. As culturas bacterianas e de fungos leveduriformes, foram mantidas a $37{ }^{\circ} \mathrm{C}$, durante $24-48 \mathrm{~h}$; as de fungos filamentosos a temperatura ambiente (28-30 ${ }^{\circ} \mathrm{C}$ ) durante dez dias. O inóculo foi preparado em solução salina $0,85 \%$ esterilizada, contendo $1 \%$ de Tween 80 . A suspensão foi padronizada pelo tubo 0,5 da escala Mc Farland e ajustada para 90\% em espectrofotômetro, para contar aproximadamente $10^{6}$ células $/ \mathrm{mL}$.

\section{Ensaio realizado pelo método de difusão em meio sólido}

Por essa metodologia, foi feita a avaliação da atividade antimicrobiana dos extratos de $D$. grandiflora frente a bactérias e fungos, incluindo o screening microbiológico e a determinação da concentração inibitória mínima (CIM). Em placas de Petri 10x90 mm, esterilizadas, foi colocado $1 \mathrm{~mL}$ da suspensão de cada microrganismo. Em seguida, $21 \mathrm{~mL}$ de agar MullerHinton e agar Sabouraud dextrose, previamente fundidos, mantidos a $50{ }^{\circ} \mathrm{C}$, foram adicionados em cada placa Após solidificação, foram feitas cavidades de $6 \times 8 \mathrm{~mm}$ de diâmetro, onde foi inoculado $50 \mu \mathrm{L}$ dos extratos em suas variadas concentrações.

Foram feitos controles, para cada microrganismo teste e com antimicrobiano padrão: cloranfenicol (30 $\mu \mathrm{g})$ para bactérias e cetoconazol $(50 \mu \mathrm{g})$ para fungos. $\mathrm{O}$ ensaio foi incubado a $37^{\circ} \mathrm{C}$ por $24-48 \mathrm{~h}$ para bactérias e fungos leveduriformes; a temperatura ambiente por 10 a 14 dias, para fungos filamentosos. Cada ensaio foi feito em duplicata e após, o período de incubação, procedeu-se à leitura e interpretação dos resultados, através de formação ou não dos halos de inibição. Foram considerados ativos, os extratos que produziram halos de inibição igual ou superior a $10 \mathrm{~mm}$ diâmetro, contra os microrganismos usados nos ensaios microbiológicos.

\section{RESULTADOS E DISCUSSÃO}

As plantas continuam a representarem uma rica fonte de drogas com diferentes princípios de atividade farmacológica, utilizada na medicina popular e, posteriormente suas ações comprovadas em teste de laboratório. A presença de substâncias antimicrobianas nos vegetais não é um fato recente. As plantas possuem várias vias metabólicas secundárias que dão origem a compostos, incluindo alcalóides, flavanóides, isoflavonóides, taninos, cumarinas, glicosídeos, terpenos, poliacetilenos que, por vezes, são específicos a determinadas famílias, gêneros ou espécies cujas funções, até pouco tempo eram desconhecidas (Agra \& Barbosa, 1990; Barbosa et al., 1987; Farnswort, 1966). Esses metabólitos produzidos pelas plantas estão relacionados ao mecanismo de defesa da planta, em resposta ao ataque de predadores como fungos, bactérias, vírus, parasitas, insetos, moluscos ou animais superiores.

Os extratos de D. grandiflora apresentaram atividade diversificada frente às bactérias e aos fungos. Assim, o extrato aquoso do caule inibiu, apenas, o crescimento de $S$. aureus (Tabela 1), enquanto que, as demais espécies foram todas resistentes ao citado produto. Comportamento similar foi observado e registrado, quanto aos resultados obtidos da avaliação da atividade antibacteriana e antifúngica do extrato etanólico da folha, caule e raiz. Não houve interferência sobre o crescimento de nenhuma das cepas testadas. Por outro lado, o extrato hidroalcoólico frente às espécies bacterianas e fúngicas, foram bem mais promissores. Os extratos hidroalcoólicos da folha, caule e raiz inibiram $T$. mentagrophytes, $M$. canis e $S$. aureus, produzindo halos de inibição entre 12 e $18 \mathrm{~mm}$ de diâmetro (Tabela 2).

$\mathrm{Na}$ Tabela 3 encontram-se os resultados da CIM do extrato aquoso do caule e hidroalcoólico do caule, raiz e folha. O micorganismo $S$. aureus foi sensível ao extrato aquoso e hidroalcoólico do caule de $D$. grandiflora, até a concentração de $2.500 \mu \mathrm{g} / \mathrm{mL}$, com respectivos halos de inibição de 12 e $20 \mathrm{~mm}$ de diâmetro. As espécies fúngicas C. albicans, T. metagrophytes e $M$. canis foram sensíveis ao extrato hidroalcoólico da raiz e folha, onde a CIM ficou registrada entre 2.500 e $10.000 \mathrm{ug} / \mathrm{mL}$. Vale ressaltar que os produtos testados não exerceram nenhuma atividade sobre as bactérias Gram negativas $P$. aeruginosa e E. coli, outras espécies de Candida, C. krusei, C. tropicalis e $C$. guilliermondii, os gêneros Trichosporon e Cryptococcus, como também, sobre os contaminantes Aspergillus, Penicillium, Geotrichum e Fusarium. Na Tabela 4, estão ponderados os valores dos resultados acerca da avaliação da atividade antimicrobiana das frações obtidas do extrato aquoso da folha de D. grandiflora. Apenas a fração acetato de etila a $3.000 \mu \mathrm{g} / \mathrm{mL}$, produziu inibição sobre o crescimento de $S$. epidermidis, C. albicans (LM-17), $T$. mentagrophytes e $M$. canis, cujos halos de inibição foram entre 10 a $20 \mathrm{~mm}$ de diâmetro (Figura 1). As frações do extrato etanólico (Tabela 5), apresentaram pouca atividade biológica sobre os microrganismos usados nos ensaios microbiológicos. Somente a fração aquosa, $3.000 \mu \mathrm{g} /$ 
$\mathrm{mL}$, inibiu o crescimento de $S$. aureus e $S$. epidermides, produzindo halos de inibição de $10 \mathrm{~mm}$ de diâmetro. Na tabela 6 , estão notificados os resultados da avaliação da CIM da fração acetato de etila da folha de D. grandiflora. A CIM da fração acetato de etila, que inibiu o crescimento de S. epidermides, C. albicans (LM-17) e T. metagrophytes foram, respectivamente, $1.500,3.000$ e $750 \mu \mathrm{g} / \mathrm{mL}$.

As bactérias Gram negativas $P$. aeruginosa e E. coli, e as espécies de leveduras do gênero Candida, Cryptococcus e Trichosporon, bem como fungos contaminantes não apresentaram sensibilidade às frações dos extratos aquoso e etanólico de Dioclea grandiflora.

Tabela 1. Valores médios dos halos de inibição ( $\mathrm{mm}$ ) da avaliação da atividade antimicrobiana do extrato aquoso de $D$. grandiflora contra bactérias e fungos em meio sólido.

\begin{tabular}{|c|c|c|c|c|}
\hline \multirow[t]{2}{*}{ Microrganismos } & \multicolumn{3}{|c|}{$\begin{array}{c}\text { Extrato aquoso } \\
(10.000 \mu \mathrm{g} / \mathrm{mL})\end{array}$} & \multirow{2}{*}{$\frac{\text { Controle }}{\text { Microrganismos }}$} \\
\hline & Folha & Caule & Raiz & \\
\hline S. aureus & 0 & 20 & 0 & + \\
\hline S. epidermides & 0 & 0 & 0 & + \\
\hline P. aeruginosa & 0 & 0 & 0 & + \\
\hline E. coli & 0 & 0 & 0 & + \\
\hline $\begin{array}{l}\text { C. albicans (ATCC- } \\
\text { 76615) }\end{array}$ & 0 & 0 & 0 & + \\
\hline C. albicans (LM-17) & 0 & 0 & 0 & + \\
\hline C. krusei & 0 & 0 & 0 & + \\
\hline C. tropicalis & 0 & 0 & 0 & + \\
\hline C. guilliermondii & 0 & 0 & 0 & + \\
\hline Trichosporon & 0 & 0 & 0 & + \\
\hline C. neoformans & 0 & 0 & 0 & + \\
\hline T. rubrum (LM-05) & 0 & 0 & 0 & + \\
\hline T. rubrum (LM-09) & 0 & 0 & 0 & + \\
\hline T. mentagrophytes & 0 & 0 & 0 & + \\
\hline M. canis & 0 & 0 & 0 & + \\
\hline A flavus & 0 & 0 & 0 & + \\
\hline A parasitticus & 0 & 0 & 0 & + \\
\hline Penicillum spp. & 0 & 0 & 0 & + \\
\hline Geotrichum spp. & 0 & 0 & 0 & + \\
\hline Fusarium spp. & 0 & 0 & 0 & + \\
\hline
\end{tabular}

+: Crescimento do microrganismo no meio de cultura isento de antimicrobiano

Tabela 3. Valores médios dos halos de inibição (mm) da avaliação da CIM dos extratos de Dioclea grandiflora Mart. ex. Benth., Fabaceae contra bactérias e fungos em meio sólido.

\begin{tabular}{lcccc}
\hline \multirow{2}{*}{ Extratos } & Concentração $(\mu \mathrm{g} / \mathrm{mL})$ & \multicolumn{2}{c}{ Microrganismos } \\
\cline { 3 - 4 } & 10.000 & S. aureus & C. albicans & T. metagrophytes \\
\hline Aquoso Caule & 5.000 & 20 & \\
& 2.500 & 16 & \\
1.250 & 12 & \\
625 & 7 & \\
& 313 & 0 & \\
\hline
\end{tabular}

As dermatofitoses, cujos agentes etiológicos pertencem aos gêneros Trichophyton, Microsporum e Epidermophyton, constituem um dos grupos de doenças mais importantes dentro da prática dermatológica, e tem causado grandes problemas de saúde pública (Lima, 1996). Neste estudo, T. mentagrophytes e $M$. canis foram os mais susceptíveis, frente ao extrato hidroalcoólico do caule.

Embora os resultados obtidos sejam importantes para o conhecimento farmacológico dessa espécie, é prudente termos cautela no uso dessa planta, e se faz necessário um aprofundamento no conhecimento de seus constituintes, para um uso seguro eficaz.

Tabela 2. Valores médios dos halos de inibição $(\mathrm{mm})$ da avaliação da atividade antimicrobiana do extrato hidroalcoólico de Dioclea grandiflora Mart. ex. Benth., Fabaceae contra bactérias e fungos em meio sólido.

\begin{tabular}{|c|c|c|c|c|}
\hline \multirow[t]{2}{*}{ Microrganismos } & \multicolumn{3}{|c|}{$\begin{array}{l}\text { Extrato hidroalcoólico } \\
\quad(10.000 \mu \mathrm{g} / \mathrm{mL})\end{array}$} & \multirow{2}{*}{$\begin{array}{c}\text { Controle } \\
\text { Microrganismos }\end{array}$} \\
\hline & Folha & Caule & Raiz & \\
\hline S. aureus & 0 & 18 & 0 & + \\
\hline S. epidermides & 0 & 0 & 0 & + \\
\hline P. aeruginosa & 0 & 0 & 0 & + \\
\hline E. coli & 0 & 0 & 0 & + \\
\hline $\begin{array}{l}\text { C. albicans (ATCC- } \\
\text { 76615) }\end{array}$ & 0 & 0 & 0 & + \\
\hline C. albicans (LM-17) & 0 & 0 & 0 & + \\
\hline C. krusei & 0 & 0 & 0 & + \\
\hline C. tropicalis & 0 & 0 & 0 & + \\
\hline C. guilliermondii & 0 & 0 & 0 & + \\
\hline Trichosporon & 0 & 0 & 0 & + \\
\hline C. neoformans & 0 & 0 & 0 & + \\
\hline T. rubrum (LM-05) & 0 & 0 & 0 & + \\
\hline T. rubrum (LM-09) & 0 & 0 & 0 & + \\
\hline T. mentagrophytes & 0 & 0 & 0 & + \\
\hline M. canis & 0 & 0 & 15 & + \\
\hline A. flavus & 12 & 0 & 0 & + \\
\hline A.. parasitticus & 12 & 0 & 0 & + \\
\hline Penicillum spp. & 0 & 0 & 0 & + \\
\hline Geotrichum spp. & 0 & 0 & 0 & + \\
\hline Fusarium spp. & 0 & 0 & 0 & + \\
\hline
\end{tabular}

+: Crescimento do microrganismo no meio de cultura isento de antimicrobiano. 


\begin{tabular}{|c|c|c|c|c|c|}
\hline Hidroalcoólico Caule & $\begin{array}{c}10.000 \\
5.000 \\
2.500 \\
1.250 \\
625 \\
313\end{array}$ & $\begin{array}{c}17 \\
12 \\
10 \\
7 \\
0 \\
0\end{array}$ & & & \\
\hline Raiz & $\begin{array}{c}10.000 \\
5.000 \\
2.500 \\
1.250 \\
625 \\
313\end{array}$ & & $\begin{array}{c}10 \\
8 \\
0 \\
0 \\
0 \\
0\end{array}$ & & $\begin{array}{c}13 \\
10 \\
0 \\
0 \\
0 \\
0\end{array}$ \\
\hline Folhas & $\begin{array}{c}10.000 \\
5.000 \\
2.500 \\
1.250 \\
625 \\
313\end{array}$ & $\begin{array}{l}0 \\
0 \\
0 \\
0 \\
0 \\
0\end{array}$ & & $\begin{array}{c}12 \\
10 \\
8 \\
0 \\
0 \\
0\end{array}$ & $\begin{array}{c}12 \\
9 \\
0 \\
0 \\
0 \\
0\end{array}$ \\
\hline \multicolumn{6}{|l|}{ Controle: } \\
\hline Cetoconazol & 50 & & 22 & 22 & 20 \\
\hline Microrganismos & & + & + & + & + \\
\hline
\end{tabular}

+: Crescimento do microrganismo no meio de cultura isento de antimicrobiano.

Tabela 4. Valores médios dos halos de inibição $(\mathrm{mm})$ da avaliação da atividade antimicrobiana das frações do extrato aquoso da folha de Dioclea grandiflora Mart. ex. Benth., Fabaceae contra bactérias e fungos em meio sólido.

\begin{tabular}{|c|c|c|c|c|c|}
\hline \multirow{2}{*}{ Microrganismos } & \multicolumn{4}{|c|}{ Frações $(3.000 \mu \mathrm{g} / \mathrm{mL})$} & \multirow{2}{*}{$\frac{\text { Controle }}{\text { Microrganismos }}$} \\
\hline & Acetato de etila & Acetato Metanol (1:1) & Metanol & Água & \\
\hline S. aureus & 0 & 0 & 0 & 0 & + \\
\hline S. epidermides & 15 & 0 & 0 & 0 & + \\
\hline P. aeruginosa & 0 & 0 & 0 & 0 & + \\
\hline E. coli & 0 & 0 & 0 & 0 & + \\
\hline C. albicans (ATCC-76615) & 0 & 0 & 0 & 0 & + \\
\hline C. albicans (LM-17) & 12 & 0 & 0 & 0 & + \\
\hline C. krusei & 0 & 0 & 0 & 0 & + \\
\hline C. tropicalis & 0 & 0 & 0 & 0 & + \\
\hline C. guilliermondii & 0 & 0 & 0 & 0 & + \\
\hline Trichosporon & 0 & 0 & 0 & 0 & + \\
\hline C. neoformans & 0 & 0 & 0 & 0 & + \\
\hline T. rubrum (LM-05) & 0 & 0 & 0 & 0 & + \\
\hline T. rubrum (LM-09) & 0 & 0 & 0 & 0 & + \\
\hline T. mentagrophytes & 20 & 0 & 0 & 0 & + \\
\hline M. canis & 10 & 0 & 0 & 0 & + \\
\hline A flavus & 0 & 0 & 0 & 0 & + \\
\hline A parasitticus & 0 & 0 & 0 & 0 & + \\
\hline Penicillum spp. & 0 & 0 & 0 & 0 & + \\
\hline Geotrichum spp. & 0 & 0 & 0 & 0 & + \\
\hline Fusarium spp. & 0 & 0 & 0 & 0 & + \\
\hline
\end{tabular}

+: Crescimento do microrganismo no meio de cultura isento de antimicrobiano. 
Tabela 5. Valores médios dos halos de inibição $(\mathrm{mm})$ da avaliação da atividade antimicrobiana das frações do extrato etanólico do caule de Dioclea grandiflora Mart. ex. Benth., Fabaceae contra bactérias e fungos em meio sólido.

\begin{tabular}{|c|c|c|c|c|c|}
\hline \multirow{2}{*}{ Microrganismos } & \multicolumn{4}{|c|}{ Frações $(3.000 \mu \mathrm{g} / \mathrm{mL})$} & \multirow{2}{*}{$\begin{array}{c}\text { Controle } \\
\text { Microrganismos }\end{array}$} \\
\hline & Acetato de etila & Acetato Metanol (1:1) & Metanol & Água & \\
\hline S. aureus & 0 & 0 & 0 & 10 & + \\
\hline S. epidermides & 0 & 0 & 0 & 10 & + \\
\hline P. aeruginosa & 0 & 0 & 0 & 0 & + \\
\hline E. coli & 0 & 0 & 0 & 0 & + \\
\hline C. albicans (ATCC-76615) & 0 & 0 & 0 & 0 & + \\
\hline C. albicans (LM-17) & 0 & 0 & 0 & 0 & + \\
\hline C. krusei & 0 & 0 & 0 & 0 & + \\
\hline C. tropicalis & 0 & 0 & 0 & 0 & + \\
\hline C. guilliermondii & 0 & 0 & 0 & 0 & + \\
\hline Trichosporon & 0 & 0 & 0 & 0 & + \\
\hline C. neoformans & 0 & 0 & 0 & 0 & + \\
\hline T. rubrum (LM-05) & 0 & 0 & 0 & 0 & + \\
\hline T. rubrum (LM-09) & 0 & 0 & 0 & 0 & + \\
\hline T. mentagrophytes & 0 & 0 & 0 & 0 & + \\
\hline M. canis & 0 & 0 & 0 & 0 & + \\
\hline A flavus & 0 & 0 & 0 & 0 & + \\
\hline A parasitticus & 0 & 0 & 0 & 0 & + \\
\hline Penicillum spp. & 0 & 0 & 0 & 0 & + \\
\hline Geotrichum spp. & 0 & 0 & 0 & 0 & + \\
\hline Fusarium spp. & 0 & 0 & 0 & 0 & + \\
\hline
\end{tabular}

+: Crescimento do microrganismo no meio de cultura isento de antimicrobiano.

Tabela 6. Valores médios dos halos de inibição $(\mathrm{mm})$ da avaliação da CIM da fração acetato de etila da folha de Dioclea grandiflora Mart. ex. Benth., Fabaceae contra bactérias e fungos em meio sólido.

\begin{tabular}{lcccc}
\hline \multirow{2}{*}{ Fração } & Concentração $(\mu \mathrm{g} / \mathrm{mL})$ & \multicolumn{3}{c}{ Microrganismos } \\
\cline { 3 - 5 } & & S. epidermides & C. albicans (LM-17) & T. mentagrophytes \\
\hline Acetato de etila & 3.000 & 15 & 12 & 18 \\
folha & 1.500 & 12 & 8 & 14 \\
& 750 & 8 & 0 & 7 \\
& 325 & 0 & 0 & 0 \\
Controles: & 162 & 0 & 0 & 0 \\
Clorofenicol & 81 & 0 & & \\
Cetoconazol & 30 & & & 22 \\
Microrganismos & 50 & 22 & 23 & + \\
\hline
\end{tabular}

+: Crescimento do microrganismo no meio de cultura isento de antimicrobiano. 

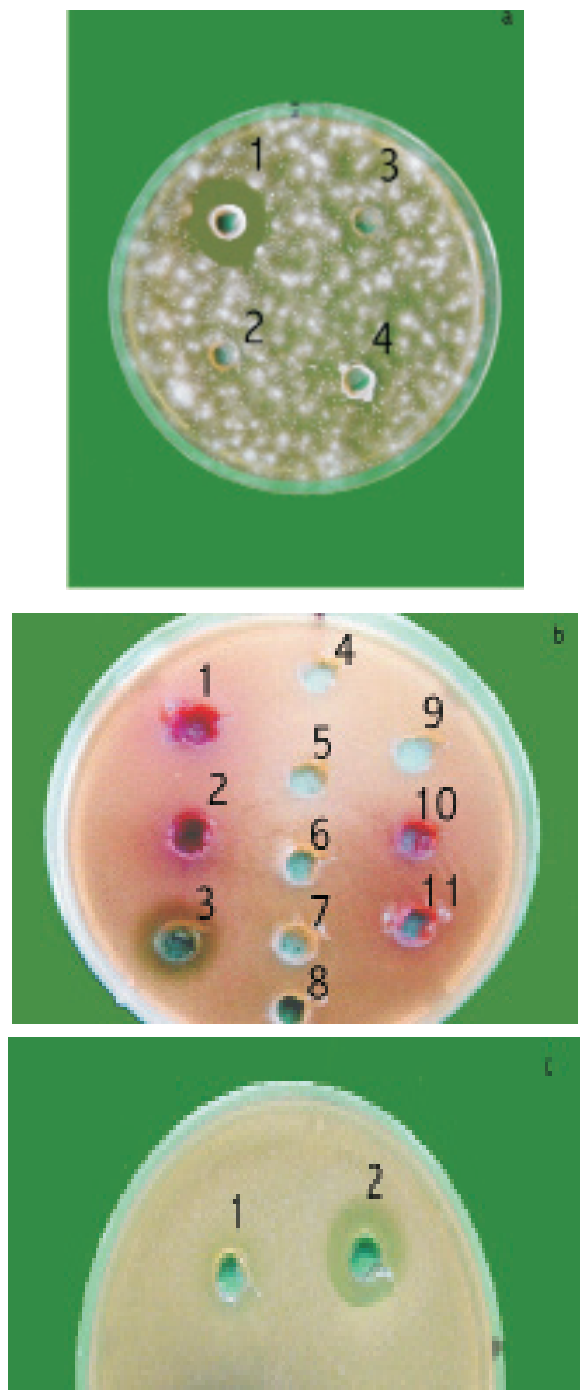

Figura 1. a) Atividade antimicrobiana da fração acetato de etila do extrato aquoso da folha de Dioclea grandiflora Mart. ex. Benth., Fabaceae, sobre T. mentagrophytes a $3.000 \mu \mathrm{g} / \mathrm{mL}$ (halo de $20 \mathrm{~mm})$; b) atividade antimicrobiana da fração acetato de etila do extrato aquoso da folha sobre $S$. epidermides a $3.00 \mu \mathrm{g} / \mathrm{mL}$ (halo de $15 \mathrm{~mm}$ ); c) atividade antimicrobiana da CIM da fração acetato de etila do extrato aquoso da folha de $D$. grandiflora sobre $S$. epidermides, 1: $1.500 \mu \mathrm{g} / \mathrm{mL}$ (halo de $12 \mathrm{~mm}$ ); 2: 3.000 $\mu \mathrm{g} / \mathrm{mL}$ (halo de $15 \mathrm{~mm}$ ).

\section{AGRADECIMENTOS}

Ao Laboratório de Tecnologia Farmacêutica da Universidade Federal da Paraíba, na pessoa da Dra. Maria de Fátima Agra, pelo suporte no deslocamento e orientação para coleta do material botânico e ao PICDT/UFPE.

\section{REFERÊNCIAS}

Agra MF, Barbosa Filho JM 1990. Levantamento da flora medicinal da Paraiba e triagem fitoquímica. Rev Bras Farm 71: 72-76.

Agra MF 1996. Plantas medicinais popular dos cariris velhos. João Pessoa: União, p.125.
Agra MF, França PF, Barbosa-Filho JM 2007. Synopsis of the plants known as medicinal and poisonous in Northeast of Brazil. Rev Bras Farmacogn 17: 114-140.

Almeida ER, Almeida RN, Navarro DS, Bhattacharyya J, Silva BA, Birbaum JS. 2003. Central antinociceptive effect of a hydroalcoholic extract of Dioclea grandiflora seeds in rodents. J Ethnopharmacol 88: 1-4.

Almeida RN, Navarro DS, Agra MF, Almeida ER, Majetich G, Batttaryya J 2000. Analgesic effect of dioclenol and dioflorin isolated from Dioclea grandiflora. Pharm Biol 38: 394-395.

Bhattacharyya J, Majetich G, Spearing P, Almeida RN 1997. Dioclenol a minor flavononol from the root-back of Dioclea grandiflora. Phytochemistry 46: 385-387.

Barbosa RCSBC, Lima EO, Maia RF, Barbosa Filho JM 1987. Espectro antimicrobiano de extratos combinados utilizados na medicina popular como antisséptico, cicatrizante e antiflamatório. Cienc Cult 39: 695.

Batista JS 1993. Estudo químico e farmacológico da casca da raiz de Dioclea grandiflora Mart ex. Benth. Dissertação de Mestrado apresenta a universidade Federal da Paraiba, $85 \mathrm{p}$.

Biavatti MW, Marensi V, Leite SN, Reis A 2007 Ethnopharmacognostic survey on botanical compendia for potential cosmeceutic species from Atlantic Forest. Rev Bras Farmacogn 17: 640-653.

Elizabetsky E 1993. Sociopolitical, economical and ethical issues in medicinal plant research. J Ethnopharmacol 32: 235239.

Farnsworth NR, Akele O, Bingel AS, Soejarto DD, Guo Z 1989. Las plantas medicinales en La terapêutica. Bol Of Sanit Panam 107: 50-53.

Funke I, Melzig MF 2006. Traditionally used plants in diabetes therapy - phytotherapeutics as inhibitors of $\alpha$-amilase activity. Rev Bras Farmacogn 16: 1-5.

Jenkins T, Bhattacharyya J, Mojetich G, Teng Q, Fátima AM 1999. Flavonoids from the root-bark of Dioclea grandifllora. Phytochemistry 52: 723-730.

Lemos VS, Freita MR, Muller B, Lino YD, Queiroga CEG, Cortes SF 1999. Dioclein a new nitric oxide and endotheliumdependent vasodilator flavonoid. J Pharmacol 386: 4146.

Lima EO 1996. Estudo das dermatófitoses em João Pessoa Paraiba e da atividade antifúngica de plantas medicinais da região contra alguns dos agentes isolados. São Paulo, Tese de doutorado, Faculdade de Ciencias Farmacêuticas, $179 \mathrm{p}$.

Mattei R, Leite JR, Tufik S 1995. A study of the pharmacological actions of Dioclea grandiflora Martiuns ex. Bentham. $M$ Journal 113: 687-692.

Oliveira CC, Siqueira JM, Souza KCB, Resende UM 1994. Avaliação da atividade antibacteriana de extratos de plantas do Cerrado. In: Simpósio de Plantas Medicinais do Brasil, Fortaleza, p.114

WHO 2002. Report on infectious diseases. World Health Organization, Geneva, Switzerland. 